\title{
Magical, Surprising and Humorous Sparkles for Creative Problem Solving
}

\author{
Eliza Pitri, Agni Stylianou-Georgiou, Antonia Michaelidou \\ University of Nicosia, Cyprus
}

\begin{abstract}
This paper is a discussion of the relationship between magic, surprise, humor, and creative problem solving, through a description of the Sparkle Street project, an attempt to involve undergraduate student-teachers in mindful artsbased experiences during a semester at the University of Nicosia, a private university in Cyprus. The project developed in the context of the students' required introductory art education, educational psychology, emerging literacy and school experience courses of their program. The general aim of the project was to engage student-teachers in arts-based problem solving while considering children as natural communicators that when given the opportunity, they can use multiple means of expression in order to discover and communicate what they know, understand, wonder about, question, feel, and imagine.
\end{abstract}

\section{Introduction}

If a child could choose between regular markers and shiny gold, silver or any other color markers with glitter, she/he would choose glitter. Is it because these materials are not on a daily basis available to most children? Or do sparkly materials have specific qualities that enchant young children? What is it that the children find magical not only related to materials but processes as well? Magic includes the element of surprise, children find surprising situations and objects humorous, and humor is a thinking quality of creative problem solvers. The relationship between the concept of magic in the sense of enchantment and cognitive processes related to creativity renders the above questions worth of consideration. This report is a discussion of the relationship between magic, surprise, humor, and creative problem solving, through a description of the Sparkle Street project, an attempt to involve undergraduate student-teachers in mindful arts-based experiences during a semester at the university.

\section{Background of the Sparkle Street Project}

The project began as an initiative of the Department of Education of the University of Nicosia, Cyprus, for acknowledging the fruitful cooperation with the local preschools where the student-teachers had their practicum. It evolved among thirty five sophomore and junior students in the context of their required introductory art education, educational psychology, emerging literacy and school experience courses of their program, and included related preschool events. They collaborated throughout a semester in the context of three courses with the initial aim of applying their knowledge towards young children's meaningful participation in arts-based activities. The student-teachers engaged in creative problem solving, humorous storytelling, constructing a magical setting and planning enchanting children's activities (see Figure 1).

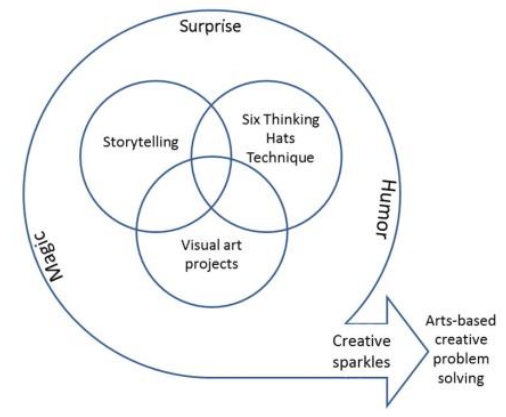

Figure 1. Magic, surprise and humor triggering student-teachers' creative sparkles facilitating artsbased creative problem solving

Magical educational activities are designed to enchant children by suddenly capturing their imagination while maximizing enjoyment, leading to creative sparkles for arts-based problem solving. Surprise in education is not considered an alternative to planning and order in schools or an alternative to repetitive practice. It has been described as the characteristic that makes a school educational, overcoming the potential of schools to be soulless institutions [1]. The Sparkle Street project was based on the notion that creative educational experiences offered to students of all ages will also be surprising and unexpected [1].

The instructors chose the storybooks from the Sparkle Street series by Vivian French as the inceptive of the project and presented them to students because, apart from glitter and sparkle on every page, they have plots that would inspire students to use tools and materials as well as strategies such as humor, in order to engage children in creative processes. The Sparkle Street books are based on the adventures of two girls that pass through a magic mirror at the back of the Shiny 
Button Café and visit the different characters in Sparkle Street, which include Barnaby Baker at his Cake Shop, Lizzie Ribbon at the Hat Shop, Wizard Stargazer at the Magic Shop, Rosa Bloom at the Flower Shop, Leo Cat at the Pet Shop, and Fairy Pink at Posy Hotel. The characters encounter problems, such as gathering scattered stardust, finding missing mice, or getting prepared for events on time, and the two girls help them solve their problems.

The Sparkle Street project started with the student-teachers studying the stories and introducing them to children during their school practicum. They guided children towards brainstorming about new adventures of the two girls, Ellie and Emma, in Sparkle Street and different problem solving situations that they would have to deal with. Upon returning on campus, the students initially combined their ideas and completed the plot with a focus on maintaining the magic of the stories and adding humor to both the plot and the characters. Then, they created settings, hats and costumes, added music to the narration, and performed it for children. After the performance on campus, the student-teachers worked with children in their preschools and helped them develop their own Sparkle Street ideas. The role of the instructors was to maintain the sparkles of Sparkle Street in the sense of keeping the studentteachers' focus during all phase of the project, on studying and applying the relationship between humorous and magical activities that enchant children and motivate them to participate in creative problem solving.

\section{Magical processes and humor for creative problem solving}

The concept of magic in education is related neither to conjuring nor superstitions. We are not talking about hanging horseshoes over classroom doors, or avoiding black cats and passing under ladders. The role of a "magician" educator is to present course content in an intriguing way in order to enchant students and make them believe in the possibilities of a seemingly impossible task. The project described in this paper was based on the notion that an educator, who finds the charm behind each goal that he/she sets for the students, is more likely to illuminate students' learning paths.

Magic includes the element of surprise as children often assign magic to unexpected situations and qualities of objects. The student-teachers planned the magic of the Sparkle Street characters and settings around unexpected attributes. By considering what is out of the ordinary for young children [2], the student-teachers aimed at surprising them. In order to enable our students to evaluate each other's and their own suggestions for surprising children, the instructors of their courses guided them through the study of humor and emphasized that children find surprising situations and objects humorous [3]. Facilitating humor as a quality of thinking related to creative problem solving [4] led us to encouraging our student-teachers to approach all their assignments with a humorous attitude and plan the plot, settings, characters and activities in ways that would make children laugh. In this way, we were aiming at facilitating humor as an attribute of creative problem solvers. The problem that the student-teachers had to solve was: What would make me laugh in the context of Sparkle Street? What would be a surprising funny, therefore enchanting process or object for young children?

Laughter, which is usually associated with humor and seen as indicating feelings like pleasure and amusement, has been considered as a communicative and interactional device in human encounters. Klein [5] describes laughter as a multisensory experience that involves our emotions, sound and visual and physical gesture. Laughter, as a social indicator of humor, is a cognitive attribute and humorous laughter involves mental thinking. Nielsen and Nielsen [6] describe humor as an attitude that makes jokes and comedy possible through understanding reality, but refusing to be constrained by it. Laughter and humor may involve non-serious attitudes and behavior; however that does not render them unworthy of being used as a teaching technique and tool for motivating children to participate in serious learning processes. Appropriately used humor has the potential to humanize the learning process, defuse tension, reduce anxiety and motivate children to think with a sparkle in their eyes (see Figure 2). Klein [2] explored the cathartic effect of humor on children and considered humor not as a form of entertainment but as an infusion of energy, which promotes children's adjustment in all ages, healthy growth and development.

There is no one theory of laughter or humor. Klein [5] summarizes the various theories of humor: the superiority theory, the relief theory, the incongruity theory, and the sociological theory. The superiority theory of humor, which is a psychodynamic theory advanced by Bergson in 1928 and can be traced back to the writings of Plato and Aristotle, emphasizes the social function of humor. It acknowledges that for something to be funny the viewer must feel some delight in seeing others come to some travail. According to the relief theory of humor discussed by Herbert Spencer and later Freud, laughter is a release of nervous energy, that is, energy associated with the repression of socially taboo or forbidden thoughts or behavior. Laughter is accomplished when feelings are built up but then are seen to be inappropriate. Humor is a socially acceptable expression of forbidden impulses, often with an accompanying release of tension through 
laughter. The incongruity theory addresses the cognitive dimensions of humorous perception. Based on this theory, humor arises through a process of acknowledging what seems to be out of sorts. Finally, the sociological theory of humor recognizes that even if the ability to understand and appreciate humor may be universal, in order for an individual to fully appreciate the humor within social interactions and in cultural contexts, he/she has to be a member of the specific culture and have internalized the behaviors, social norms or values of the culture. The social theory contends that humor is a vehicle for establishing more satisfying group interactions and transmitting cultural norms. The Sparkle Street project was based on the incongruity theory of humor, specifically considering that humor development depends on creativity since conventional thinking is based on congruity, compatibility and clarity of definition, whereas, creative thinking is based on incongruity and incompatibility.

Loizou [7] suggests that there are two theories that best describe young children's humorous behavior: the Theory of the Absurd, which includes events that are out of the ordinary and violate children's existing schemata and the Empowerment Theory, which describes young children's ability to violate the expectations of adults and use humor to empower themselves. Sensory and perceptual shifts, such as peekaboo, that amuse babies and cause them to laugh do not constitute humor. Humorous situations are those which cause a more sophisticated kind of psychological shift, a conceptual shift. As children grow, they not only name things, properties and events in their experiences, but they also come to see certain patterns among them and develop a system of connections between them. Ice for example is always cold; therefore, when they see ice they expect it to be cold. At this point of development the child begins to enjoy humor based on very simple conceptual shifts at first. Children often find something humorous simply because they have not experienced something like it before.

Most adult humor is based on experiencing or imagining incongruity, that is, based on the conceptual shift from what the person would expect a given thing or situation to be, to an awareness that the thing or situation is not like that. The surprise is caused by the unusual features of a thing or a situation that the person had experienced before, which violate part of the person's conceptual system. In the simplest kind of children's humor, however, their conceptual system is not violated by something incongruous since experiences are new and children have no expectations about what features they should have. The shift is from an ordinary state of awareness in which children understand the things they are experiencing, to a surprised state of confronting some new kind of thing or event for which they have not prepared a place in their picture of the world [8].

In a more advanced type of humor what is funny to children is not something totally unfamiliar to them but something incongruous according to their conceptual system [9]. A child cannot experience and enjoy humor until he/she comes to understand that the incongruities he/she is being presented with are only playful rearranging of reality, otherwise early experiences with conceptual shifts that are supposed to be amusing are instead puzzling or even distressing. A child confronted by an adult saying, "I' m going to eat you up," has to have a solid grasp of his/her conceptual system in order to feel comfortable in having it violate.

The student-teachers' attempt to approach young children's humor was initially focused on causing and facilitating children's enjoyment by creating objects with simple, perception-oriented incongruities, such as unusual costumes for the Sparkle Street characters in terms of colors and materials. In the Art Education course, they used plastic bags and curtain fabric samples with contrasting colors for the outfits and constructed about 2 meters-tall, three dimensional and funny shops from Sparkle Street (see Figure 2). The roof of

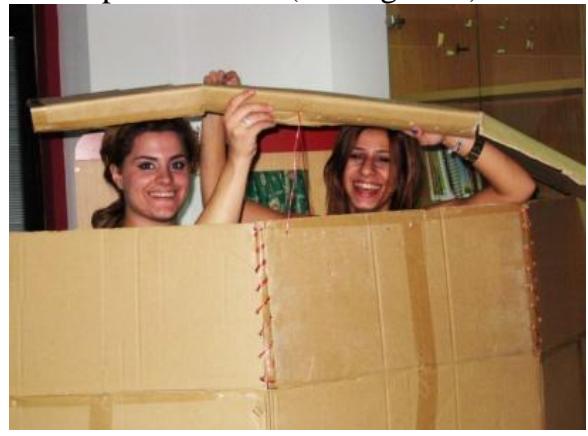

Figure 2. When humor is the focus, processes are engaging, individuals are self-motivated and artmaking is playful

Barnaby Bakers Cake Shop, for example, resembled the icing of a cake with a glazed cherry on top, Wizard Stargazer's Magic shop had spider web instead of glass windows and Leo Cat's Pet Shop walls made reference to Dalmatian dogs, playfully rearranging children's reality (see Figure 3). The characters' outfits were highlighted by oversized paper-maché hats (see Figure 4), which also violated individuals' existing schemata.

In order to engage student-teachers in creative problem solving that would enhance their understanding of humor and understanding in general, the art instructor assigned them with the following project: "You are interior designers. The owner of Shiny Button café hired you to suggest creations for decorating the café's tables. Think about what objects you would find on a table of this café, decide what type of object you would work with and think about what materials you would use 
to create something site specific". For students who were not part of this assignment, the objects and settings in the classroom that turned into Shiny Button café (see Figure 5), violated their existing schemata, of what a classroom, a vase, a candle holder looks like, and therefore, seemed humorous to them.

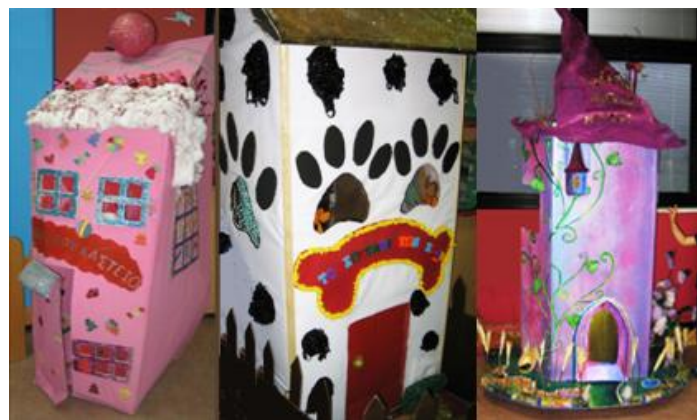

Figure 3. Three dimensional Sparkle Street shops playfully rearranging children's reality

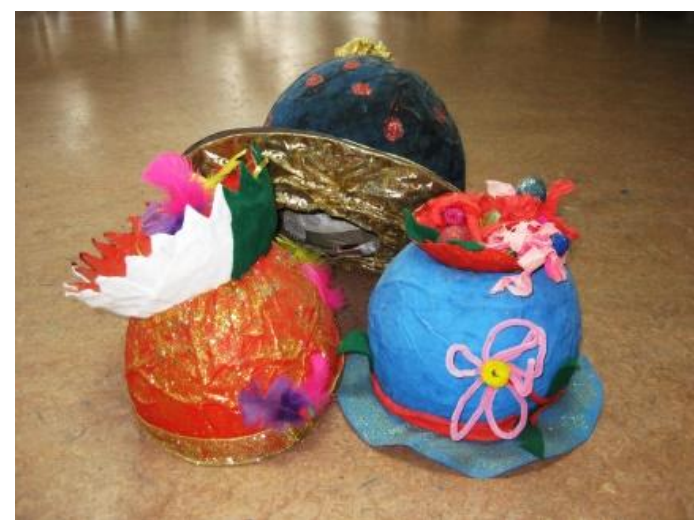

Figure 4. Simple, perception-oriented incongruities can be enchanting for young children

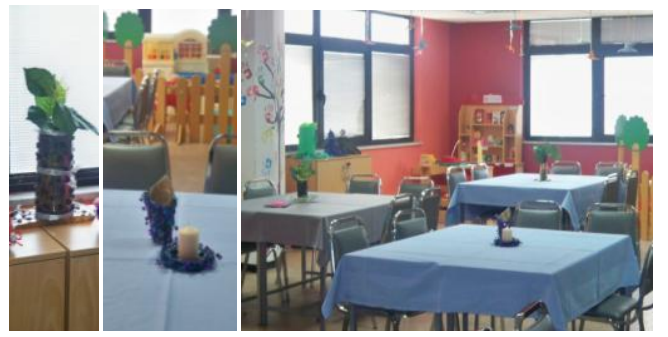

Figure 5. Transforming a classroom into Shiny Button café

Another unexpected schema violation was caused by a different group of student-teachers who transformed the door frame of the classroom into the magic mirror that let whoever entered the specific classroom in Sparkle Street, the room where the Sparkle Street houses were stored.

The student-teachers who worked in the Sparkle Street project attempted to activate children's more sophisticated sense of humor, in an intellectually and emotionally appropriate manner, while planning a plot for an interactive performance with school children from the preschools engaged in the practicum program as audience. Young children are amused by incongruities [7], such as the idea of a flying vacuum cleaner, or a mirror frame that could transport a person form the real world to fantasy, glitter rain etc., which are incongruities based on the violation of conceptual representations. Such incongruities guided the student-teachers' magical storytelling for their own and eventually for children's creative problem solving.

\section{Magical storytelling and creative problem solving}

As Andrelchik [10] pointed out, getting students to see that reading and writing do not exist in diametrical opposition to artmaking is a challenge and the meaning of literacy in art education needs exploring. Starting from reading the Sparkle Street children books, we attempted to combine with our student-teachers multiple forms of literacy (textual, oral, visual) in order to create an engaging, artsbased learning context for children. Magic and humor are the techniques we found that facilitated this attempt the most. We encouraged our studentteachers to come up with their own Sparkle Street stories beginning with a somewhat realistic but problematic situation. Perplexing everyday problems and events stimulate children's understanding of the how and why of such situations, and to seek solutions [11]. The student-teachers came up with the perfect problem: The sparkle has disappeared from Sparkle Street! Where has all the glitter gone? How would each character react? How would they get it back? Which other character might contribute to the problem solving process?

This problematic situation was an opportunity to utilize de Bono's [12] Six Thinking Hats technique in order to encourage student-teachers to adopt multiple perspectives while being engaged in problem solving. Through the six thinking hats technique, the Educational Psychology instructor aimed to engage student-teachers in collaborative problem solving and extend their way of thinking about their Sparkle Street stories by wearing a range of different 'thinking' hats. Each one of the six hat colors represents a way of thinking (see Figure 6).

Six colored hats (blue, white, red, yellow, green, black) represent six modes of thinking. Wearing a hat directs thinking. When wearing the white hat, one focuses on information available, the objective facts of the problem, what is needed and how it can be obtained.

The red hat encourages thinking of emotions, feelings, intuition, and hunches about the alternatives. 


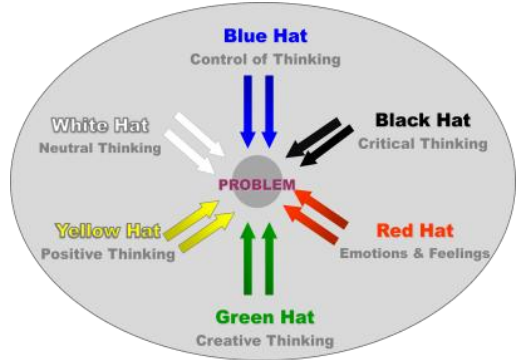

Figure 6. De Bono's Six Thinking Hats technique for creative problem solving

The yellow hat represents optimistic thinking, asking thinkers to list the benefits of the ideas proposed. Wearing the black hat, engages thinkers in a devil's advocate role, being judgmental and critical about the merits of the ideas. The green hat encourages creative thinking. When wearing this hat, one can generate as many ideas as possible on how the problematic case could be handled. Finally, the blue hat allows for coordination of the thinking process. A person who is familiar with the Six Thinking Hats technique usually is chosen to wear the blue hat so as to be able to control the sequence of the hats that will be used by thinkers and pose questions that will prompt thinkers to think.

Student-teachers were asked to put on a specific color hat at the same time (parallel thinking) to solve the Sparkle Street problem. The Educational Psychology instructor wore the blue hat and regulated the thinking process, setting the sequence of the hat and a time limit for each hat for efficiency. Initially, the instructor asked student-teachers to put on the white hat (see figure 7) posing the following question: "What data do we have so far for Sparkle Street?" Student-teachers focused on available information about the Sparkle Street characters and gathered information from the children book series needed to solve the problem. Examples of the facts were the following: "the mirror can be used to transfer the girls from the real world to the fantasy world", "the sparkle is missing", "the girls are young", "the magician has the power to bring the sparkle back", "all the characters of the story can be found in the buildings that they live (i.e. Wizard Stargazer in the magic shop, Rosa Bloom in the flower shop, Barnaby Baker in the cake shop, Lizzie Ribbon in the Hat shop, Kitty Word in the book shop, Leo Catt in the pet shop, etc)".

Student-teachers were ready to put on the red hat (see figure 8) so as to release their feelings about the fact that sparkle was missing which might have affected all other thinking during the problem solving process. Student-teachers said: "Christmas is approaching and everything is dull, the sparkle is missing!" expressing feelings of sadness, despair, fear, anxiety, curiosity and anger. Then, studentteachers put on the green hat (see figure 9) in order to brainstorm ideas about how to solve the problem.
The following questions were used to prompt thinking about the Sparkle Street problem: "How do you think the sparkle has disappeared? How can we get back the sparkle?" Student-teachers came up with many creative ideas: "Fairy Tikitigklon will come to show the path to the characters of the story so that the sparkle can be found", "the footprints of Bad Roufix who sucked the sparkle were discovered and the sparkle can be found and dropped back to Sparkle Street", "a spell can be made to put the witch that stole the sparkle to sleep so the characters can get the sparkle back", "the girls (Ellie and Emma) can go and buy glitter", "everybody who lives in Sparkle Street offers something from their stores and the magician can transform it into sparkle", "send a letter to Santa Claus asking him to come and bring sparkle to Sparkle Street", "everybody can dance until it starts raining sparkle".

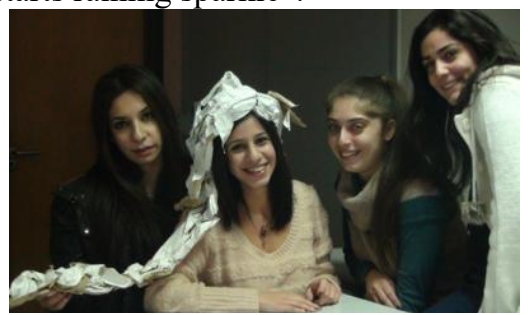

Figure 7. Wearing the white hat helps the problem solver focus on available information

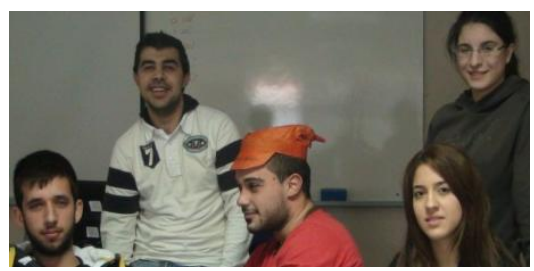

Figure 8. The red hat encourages thinking of emotions and intuition during problem solving

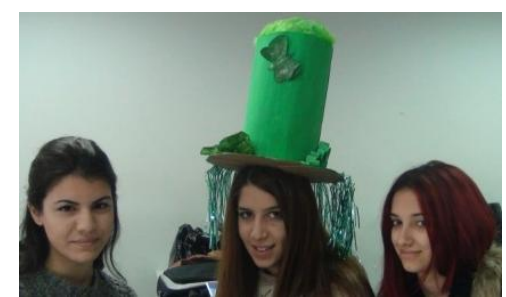

Figure 9. The green hat encourages brainstorming and alternative solutions to problem solving

After brainstorming, student-teachers were asked to put on the black hat (see figure 10) to be critical about the merits of their ideas. The instructor posed the following questions: "What difficulties could we encounter in our attempt to get back the sparkle? What are the risks?" A productive dialogue followed where student-teachers evaluated the ideas that were proposed and thought of the dangers the characters might encounter if they adopt one of the suggested solutions. For example, "what if the sleeping spell 
meant to be used against the witch cannot work since she has magic power?"

After the black hat, it was time for the yellow hat (see figure 11) to be put on by posing the following question: "Can we succeed in bringing back the sparkle?" Student-teachers were encouraged to engage in positive thinking listing the benefits of their ideas. They managed to be optimistic that a solution could be found and took some time to discuss the value of the ideas proposed while having the other hats on. Some of their ideas were the following: "Don't worry, sparkle will be found. We can print announcements and put them on the street", "announcements can be made in the mass media ( $\mathrm{TV}$, radio, internet) so that we are notified when it is found", "we always find solutions! We will find a solution to this problem.", "let's try all together, we can succeed in bringing the sparkle back!", "we can recruit a dog from Leo Catt's pet shop to help us (with his smell) find the sparkle.", "it would be a good idea, if each character checked in his/her store to look for the sparkle.", "Don't panic! Sometimes we lose something but we find it at the end", "sparkle is not gone forever, it's somewhere and it will return to Sparkle Street." After listing all the ideas proposed by putting on the different colored hats, student-teachers were ready to finalize their own collaborative Sparkle Street story.

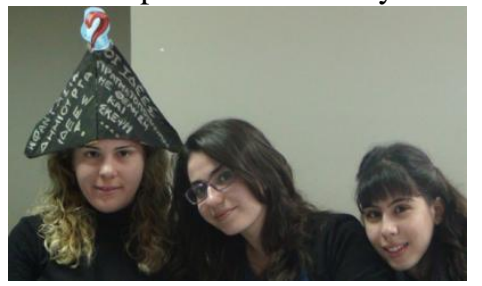

Figure 10. Wearing the black hat encourages problems solvers to be judgmental and critical about ideas

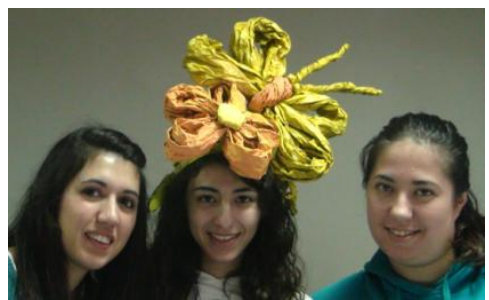

Figure 11. The yellow hat represents optimistic thinking during problem solving

In the context of the courses Emerging Literacy and School Experience, the student-teachers created new characters for their Sparkle Street. Brainstorming and viewing reality through alternative perspectives in order to create an enchanting and humorous story let the studentteachers incorporate Ellie's doll having private conversations with her when being on Sparkle Street, a dancing flower pot, a squealing door bell, bottles filled with iridescent mystery concoctions, multicolored shooting stars (see Figure 12).
Additionally, a flock of cranes with super senses could arrive in Sparkle Street whenever the habitants needed them, gladly offering important information for problem solving. This attempt was based on the premise that children's animistic thinking not only allows but also requires dreamlike features in characters or objects of enchanting stories.

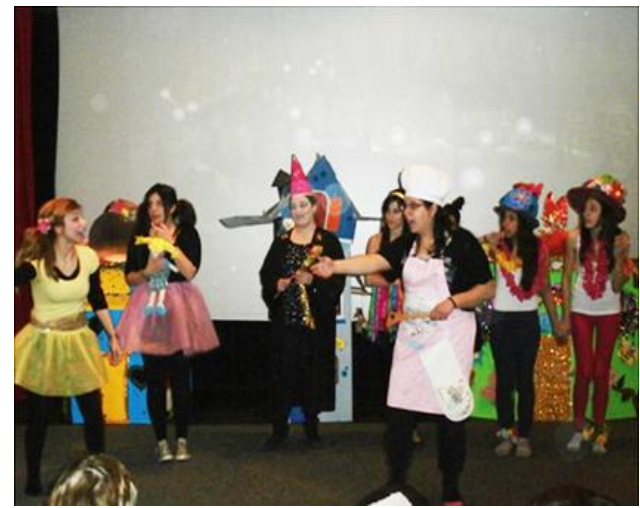

Figure 12. Both the plot and the characters' physical appearance were based on what children find humorous, such as extraordinary transfiguration and fantasy figures, events and objects

Student-teachers' magical storytelling started from something concrete (a mirror), building suspense by passing through the mirror and presented extraordinary objects and situations that allowed continuous problem solving and opportunities for developing new twists and turns. Similar to what Hathaway [13] describes as the three acts of producing art works when the art teacher assumes the role of a magician, our student-teachers' magical story started with the "pledge" for building mystery and suspense in order to ensure the audience attention, continued with the "turn" when something unexpected happens, and ended with "the prestige" and all the problems solved. What Hathaway [13] describes happening in the art classroom, guided the acts of our student-teachers' story in an attempt to perform a thirty-minute magic trick for preschool children on campus. Act one, the motivational set, began with the characters in front of the closed curtain and the mirror in the center of the stage right at the point where the two side curtains meet. The children did not know what the curtains concealed but in the presence of a two-meter-tall frame, they could not help but wonder. Then, act two, the turn, began when Emma and Ellie passed through the mirror, the curtains opened, the mirror was moved on the side, and the girls were in Sparkle Street. All the action and interaction planned took place during the second act. The student-teachers, as actors and magicians, had to present problems and encourage children to participate by suggesting solutions. The final bow, the prestige, was achieved when the witch returned the sparkle to Sparkle Street and the characters and the children had a party to celebrate. 
During the final plans for the performance of their Sparkle Street story, the student-teachers planned their interaction with the audience. They thought of questions related to each character's most entertaining attribute in order to engage the audience in creative problem solving during the performance. Creative questions motivate an audience to think creatively. Ellie, the naïve one from the two girls that visit Sparkle Street, wondered if it would be possible that the missing sparkle was in Old McDonald's basement. Later when they could not find any of the habitats at their shops, since they had gathered at the city plaza to talk about the missing sparkle, Ellie wondered if they had taken the sparkle and moved to exotic destinations. The Sparkle Street habitats at the same time also wondered what happened to their sparkle. Could it be sucked by the anteater that leaves in the neighborhood? Did the bear hide it in the beehives? Could it be washed off by heavy rain? Aliens took it? Wizard Stargazer's rival stole it and transformed it into a beautiful princess? The sensitive Lizzie Ribbon that would repeatedly pass out every time they encounter a problem, asked children to help with ideas of how to make Witch Foufiktra come back to Sparkle Street to prevent another passing out. Wizard Stargazer wondered what he could offer the witch to allure her to return to Sparkle Street. Would a magic concoction that would make her hair dotted work or would a magic make-up powder that covers the skin with turquoise sparkly molds be better?

The characters of the play and the audience agreed that a fair way to proceed with problem solving would be initially to talk to Witch Foufiktra in order to find out why she took the glitter from Sparkle Street and view the situation from her perspective. Allowing others to explain their stance and point of view before drawing conclusions for problem solving is an approach to, not only provide problem solvers with additional perspectives for alternative solution possibilities, but also to avoid prejudice and facilitate empathy during problem solving. The Sparkle Street characters and the audience explained to the witch the importance of glitter for Sparkle Street and watched her getting upset in a silly manner when she realized the she was actually not doing the habitants a favor when she collected the glitter with her flying vacuum earlier that day. They all also agreed that a nice way to thank the misunderstood witch for returning the glitter was offering her a pair of glitter-blocking glasses to put on every time she flew over Sparkle Street. Finally, they baked her favorite cake and threw a party for celebrating the happy ending.

\section{Sparkle Street preschool emergent inspirations}

The Sparkle Street project on campus was an overdose of glitter and creative problem solving for student-teachers and the visiting children. Upon returning to their preschool after participating in the student-teachers' performance on campus, a group of children were inspired to transform a corner of their classroom into Lizzie Ribbons' hat store. They decorated the exterior of their hat store with ribbons, cut and colored two-dimensional paper hats to decorate the interior and created the shop's sign (see figure 13). After decorating straw hats with ribbons and laces they performed for their classmates as Lizzie Ribbons (see Figure 14). Their work had similar characteristics with the student-teachers' project in the sense that children enjoyed themselves solving problems and engaging in collaborative creative expression. It felt fulfilling for the studentteachers to see that their Sparkle Street sparked children's humorous and enchanting creative expression.

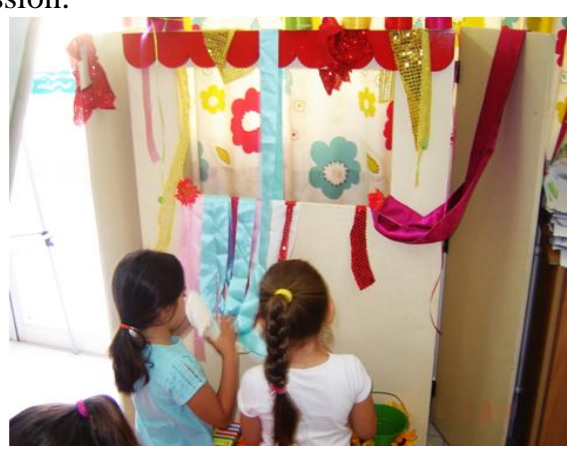

Figure 13. The enchanting experiences of Sparkle Street on campus inspired collaborative creative expression in a preschool context

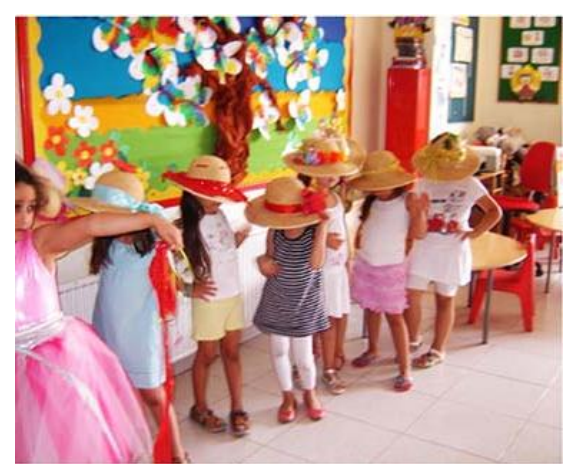

Figure 14. Children's humorous and enchanting creative expression inspired by Sparkle Street.

Children's ideas would have never been materialized if their teachers had not shared a pedagogy that values emergent curriculum. Reggio Emilia educators have long advocated for the importance of negotiating the curriculum with children, describing pre-planned curriculum as teaching without learning. The Reggio educators 
share a theoretical foundation for curriculum development, which is manifested through the idea that children should be given the opportunity to explain what they have experienced. This is accomplished through emergent curriculum planning, since the potential of children could be stunted when the endpoint of their learning is formulated in advance [14].

The process of emergent curriculum and activity planning begins as teachers observe and interact with children, and lay out general educational objectives, without formulating the specific goals for each activity in advance. Instead, they express general goals and make hypotheses about what direction the activities might take, consequently, they make appropriate preparations. These hypotheses are flexible and adapted to the needs and interests of the children. The goal of planning without preconceived objectives is to allow the children to make choices and receive feedback from others to construct knowledge. Reggio Emilia educators emphasize that having respect for the children does not mean that the teachers should blindly follow all their ideas but they should think about them to determine which ones should be pursued and how they might be supported [15].

\section{Conclusions}

Reflecting upon student-teachers and participating children's activities throughout the Sparkle Street project revealed connections to Project Zero's "Indicators of Playful Learning" [16]. The team of Harvard's Project Zero share ideas from a research initiative, which explored how playful learning can assume a central role in schools. They underline the importance of playful learning for intellectual, social, emotional, and physical development and describe delight, choice and wonder as indicators of playful learning. Studentteachers during the Sparkle Street project, for example, expressed feelings of delight when they were excited to take the Sparkle Street book series to the preschool, write their own script based on related problem solving, and construct their Shinny Button objects and Sparkle Street shops. Student-teachers anticipated wearing both their thinking hats and the oversized Sparkle Street characters' hats. The participating children's delight was evident through their constant smiles and silly ideas to problems presented during the performance at the university, as well as their catwalk and posing as Lizzie Ribbons.

The Sparkle Street project facilitated decision making by participants both at the university and the preschool. Student-teachers made collective choices for defining the goal, process, and tools and materials for artmaking when they were creating objects for the Shiny Button Café or constructing the
Sparkle Street stores. They also demonstrated collective choices during script writing by wearing de Bono's Thinking Hats to develop and share ideas about staging challenges. Student-teachers' individual choices included selecting a role during the performance, costume and other equipment, and defining the amount of personal time that would be devoted to rehearsals. Preschool children's collective choices included decision making concerning the part of the classroom that could be transformed into Lizzie Ribbon's hat store, how the exterior and interior should look like, and who could be the best contributor to materializing each idea. Children made choices for the duration of their activities with the constraints of the general school daily schedule, chose who to collaborate with and when to move around the various spaces of the classroom. Their common interest in fashion did not collide with teachers' learning goals, therefore, children experienced choice and felt the autonomy of bringing extra materials from home to plan their Lizzie Ribbon's catwalk the way they wanted to. Choice empowers playful learners and provides a sense of autonomy, ownership, spontaneity, and intrinsic motivation [16].

Wonder entails playful learners' experience of curiosity, novelty, surprise, and challenge [16]. This was the characteristic that kept student-teachers as well as preschool children engaged and fascinated during Sparkle Street activities. Student-teachers' wonder involved exploring the possibilities of cardboard paper for the Sparkle Street buildings construction, inventing ways to make over-sized hats functional, imagining and assuming roles based on the book characters, improvising and taking the risk of asking for children's opinions during their performance. Preschool children's wonder was specifically observed at the beginning of the performance when the stage opened to reveal the Sparkle Street. They seemed surprised by the unexpected difference between the plain curtain and the detailed glittering decoration of every object on stage. The plot and the staging seemed enchanting for the majority of the children and kept their attention focused throughout the performance as they were more than willing to respond to the characters' questions. Sparkle Street participants wondered in one way or another, since wonder can emerge from the ordinary to the extraordinary and be experienced through play with materials, ideas, perspectives, music, symbols, words, languages, stories, movement, or other modes of expression [16].

Playfulness was evident in the enchanting activities planned by instructors for student-teachers, in the activities planned by student-teachers for preschool children, as well as in the activities planned by the children themselves in their preschool classroom. The Sparkle Street project at the university and the preschool context provided 
examples of how everyone involved engaged in creative problem solving through playful learning experiences.

Do preschool teachers need to recruit a class of undergraduates to make their children's eyes sparkle, solve problems and light artmaking? A magic mirror, Lizzie Ribbon's hat, Wizard Stargazer's wand, a dotted purple egg from Barnaby Baker's cake shop or a Rosa Bloom's magic sprinkler or watering-can would be a more practical facilitator of creativity in a regular classroom. Art works, artistic processes and creative art making can surprise, transform, excite, enchant. Children need the magic and the arts combined with various forms of literacy can offer it. Young children that learn to engage in creative problem solving either by 'putting on' one of de Bono's "Six Thinking Hats", or engage in arts-based problem solving and storytelling sparkle, not only in Sparkle Street, but in every situation.

\section{References}

[1] J. Stern, "Surprise in Schools: Martin Buber and dialogic schooling”, FORUM 55(1), 2013, pp. 45-58.

[2] A.J. Klein, Humor in children's lives. Praeger, Westport, CT, 2003.

[3] E. Pitri, "Children's funny art and the form it can take over time", International Journal for Education through Art 7(1), 2011, pp. 81-96.

[4] E. Pitri, "Skills and dispositions for creative problem solving during the art making process", Art Education 66(2), 2013, pp. 41-46.

[5] S.R. Klein, Art and Laughter. Palgrave Macmillan, New York, NY, 2007.

[6] A.P. Nielsen, \& D.L.F. Nielsen, Encyclopedia of 20th century American humor. Oryx Press, Westport, CT, 2000.

[7] E. Loizou, "Disposable cameras, humour and children's abilities", Contemporary Issues in Early Childhood 12(2), 2011, pp. 148-162.

[8] E. Hoicka, \& N. Akhtar, "Early humour production", British Journal of Developmental Psychology 30(4), 2012, 586-603.

[9] C. Canestrari, \& I. Bianchi, "Perception of Contrariety in Jokes", Discourse Processes: A multidisciplinary Journal, 49(7), 2012, 539-564.

[10] H. Andrelchik, "Reconsidering literacy in the art classroom”, Art Education 68(1), 2015, pp. 7-11.

[11] B. Bettellheim, The uses of enchantment: The meaning and importance of fairy tales, Viking Penguin, New York, NY, 1986.

[12] E. De Bono, Six Thinking Hats. Back Bay Books, New York, NY, 1999.
[13] N.E. Hathaway, "Smoke and mirrors: Art teacher as magician", Art Education, 66(3), 2013, pp. 9-15.

[14] C. Edwards, L. Gandini, \& G. Forman (Eds.). The Hundred Languages of children. The Reggio Emilia experience in transformation, Praeger, Santa Barbara, CA, 2012.

[15] L. Gandini, \& C. P. Edwards (Eds.), Bambini. The Italian approach to infant / toddler care, Teachers College Press, New York, NY, 2001.

[16] Project Zero, "Towards a Pedagogy of Play", 2016. Retrieved from http://www.pz.harvard.edu/sites/default/ files/Towards\%20a\%20Pedagogy\%20of\%20Play.pdf (Access Date: 4 September 2016) 